\title{
Involvement of leptin in the molecular physiology of the placenta
}

\author{
Malena Schanton ${ }^{1,2}$, Julieta L Maymó ${ }^{1,2}$, Antonio Pérez-Pérez ${ }^{3}$, Víctor Sánchez-Margalet ${ }^{3}$ and \\ Cecilia L Varone ${ }^{1,2}$ \\ ${ }^{1}$ Departamento de Química Biológica, Universidad de Buenos Aires, Facultad de Ciencias Exactas y Naturales, \\ Buenos Aires, Argentina, ${ }^{2}$ Universidad de Buenos Aires, CONICET, Instituto de Química Biológica de la Facultad de \\ Ciencias Exactas y Naturales (IQUIBICEN), Buenos Aires, Argentina and ${ }^{3}$ Departamento de Bioquímica Médica y \\ Biología Molecular, Hospital Universitario Virgen Macarena, Facultad de Medicina, Universidad de Sevilla, \\ Sevilla, España \\ Correspondence should be addressed to C L Varone; Email: cvarone@qb.fcen.uba.ar
}

\begin{abstract}
Leptin is a homeostatic regulator in the placenta where it promotes proliferation, protein synthesis and the expression of tolerogenic maternal response molecules such as HLA-G. Leptin also exerts an anti-apoptotic action in placenta controlling the expression of p53 master cell cycle regulator under different stress conditions. On the other hand, leptin is an integrative target of different placental stimuli. The expression of leptin in placenta is regulated by hCG, insulin, steroids, hypoxia and many other growth hormones, suggesting that it might have an important endocrine function in the trophoblastic cells. The leptin expression is induced involving the CAMP/PKA or CAMP/Epac pathways which have profound actions upon human trophoblast function. The activation of PI3K and MAPK pathways also participates in the leptin expression. Estrogens play a central role during pregnancy, particularly $17 \beta$-estradiol upregulates the leptin expression in placental cells through genomic and non-genomic actions. The leptin promoter analysis reveals specific elements that are active in placental cells. The transcription factors CREB, AP1, Sp1, NFKB and the coactivator CBP are involved in the placental leptin expression. Moreover, placental leptin promoter is a target of epigenetic marks such as DNA methylation and histone acetylation that regulates not only the leptin expression in placenta during pregnancy but also determines the predisposition of acquiring adult metabolism diseases. Taken together, all these results allow a better understanding of leptin function and regulatory mechanisms of leptin expression in human placental trophoblasts, and support the importance of leptin during pregnancy and in programming adult health.

Reproduction (2018) 155 R1-R12
\end{abstract}

\section{Introduction}

The placenta is the organ that establishes fetal maternal interaction during pregnancy. It plays a critical role in conveying water, oxygen, nutrients and growthregulating signals from the maternal compartment to the fetus. The placenta also produces a broad spectrum of hormones and growth factors that play key roles in maintaining a proper flux of nutrients between the mother and the fetus. Different hormones, growth factors and cytokines may therefore enhance embryo implantation and fetus growth. In this context, leptin has emerged as a key placental hormone that influences various aspects of placental function and fetal development in humans and primates.

Leptin hormone is the product of the $L E P$ gene. It was discovered in 1994 by Zhang et al. (1994) and is a $16,000-M W$ non-glycosylated polypeptide of 146 amino acids. Its structure reveals a four-helix bundle similar to the long-chain helical cytokine family (Flier 1995).
Leptin was first described to be secreted by the adipose tissue, with the function of food intake and energy expenditure modulation (Houseknecht \& Portocarrero 1998). Nevertheless, leptin is now considered as a multifunctional hormone produced by different tissues and organs such as the stomach, skeletal muscle, pituitary cells and placenta (Reitman et al. 2001). Leptin exerts pleiotropic effects such us the modulation of thermogenesis, angiogenesis, hematopoiesis, osteogenesis, chondrogenesis, neuroendocrine and immune functions as well as arterial pressure control (Dos Santos et al. 2015). Leptin has also been implicated in reproductive functions, including menstrual-cycle regulation, oocyte maturation, implantation, embryo development and lactation (Cervero et al. 2005, Henson \& Castracane 2006, Israel \& Chua 2010). In this regard, leptin is an important player in the regulation of fertility. In fact, the absence of leptin action caused by mutations in the leptin gene or leptin receptor gene ( $L E P R)$ has been 
linked to infertility in rodents and humans (Hohos \& Skaznik-Wikiel 2017).

A relevant role of leptin in implantation has been proposed. Embryo implantation is the most critical step in a successful pregnancy. The blastocyst becomes closely connected and invades the maternal endometrial surface (Aplin 2000, Su \& Fazleabas 2015). A large number of mediators are involved in this early fetalmaternal connection, including hormones, adhesion molecules, cytokines, growth factors, lipids and others (Achache \& Revel 2006). It was reported that the endometrium and preimplantation embryos possess $\angle E P R \mathrm{mRNA}$, indicating that they are targets for leptin action. Furthermore, leptin mRNA is expressed in the blastocyst suggesting an active leptin role in the fetalmaternal dialog (Cervero et al. 2004).

In trophoblasts cells, the synthesis and secretion of leptin as well as its functional receptors were widely demonstrated (Masuzaki et al. 1997, Senaris et al. 1997), suggesting that leptin may act as a modulator of placental endocrine function (Coya et al. 2006). In this way, it was reported that leptin increases the matrix metalloproteinase expression in cytotrophoblasts, facilitating the implantation process (Castellucci et al. 2000). Besides, leptin has physiological effects on placenta development including angiogenesis, growth and immunomodulation (Henson \& Castracane 2006). Previous studies demonstrated that leptin increases the release of pro-inflammatory cytokines and prostaglandins from human placental explants, stimulates hormone and cytokine production (Cameo et al. 2003) and regulates fetal growth and development (Henson \& Castracane 2006), further implicating leptin as a modulator of placental function.

The human LEPR gene encodes by alternative splicing several transmembrane proteins with different intracellular C-terminal domains and one soluble isoform that lacks the transmembrane region. All leptin receptor isoforms are expressed in the placenta including the soluble form (Gorska et al. 2010). Leptin and its receptor have structural and functional similarities with the IL6 family of cytokines (Madej et al. 1995, Tartaglia et al. 1995). Leptin stimulates Janus kinase (JAK)-signal transducers and activators of transcription (STAT) pathway by promoting JAK-2 and STAT-3 tyrosine phosphorylation in JEG-3 cell line, as well as in trophoblastic cells from human-term placenta. The STAT-3 activation has been correlated with trophoblast invasiveness (Corvinus et al. 2003). We have demonstrated that leptin activates other signal transduction pathways both in cell culture and in human-term placenta explants (Perez-Perez et al. 2008) such as the MAPK and PI3K pathways. The activation of the MAPK pathway mediates proliferative responses in different systems (Takahashi et al. 1997, Tanabe et al. 1997, Bjorbaek et al. 2001, Martin-Romero \& SanchezMargalet 2001). The activation of PI3K, PKB and mTOR has been described to regulate differentiation of human trophoblasts (Pollheimer \& Knofler 2005).

This review focuses on current knowledge of leptin as a homeostatic regulator in the placental cells as well as the regulation of leptin expression in trophoblastic cells and the signal transduction pathways involved. Besides, the transcription factors mediating its induction will be discussed. Finally, epigenetic leptin promoter modifications and their consequences in programming will be analyzed.

\section{Leptin is a homeostatic regulator in the placenta}

Leptin is implicated in inducing trophoblast cell proliferation and survival. In human pregnancy, trophoblast cells differentiate into two distinct pathways. In the villous pathway, cytotrophoblasts fuse to form a specialized syncytium called syncytiotrophoblast on the outer layer of the placental villi (Carson et al. 2000). The syncytiotrophoblast forms a barrier between maternal and fetal circulations and is important for the normal immunological, endocrine and nutritional functions of the placenta (Heazell \& Crocker 2008). In the extravillous pathway, cytotrophoblasts proliferate and differentiate into an invasive phenotype that penetrate into the maternal decidua and myometrium and remodel uterine arteries (Su \& Fazleabas 2015). We have demonstrated that leptin enhances BeWo, JEG-3 and Swan-71 cell proliferation in a dose-dependent way. After leptin treatment, cyclin D1, one of the key cell cycle signaling protein, is upregulated and cells show a displacement toward G2/M phase. Moreover, leptin induces not only protein synthesis but also the phosphorylation state of EIF4EBP1 and EIF4E in both JEG-3 and trophoblastic cells in a dose-dependent manner (Perez-Perez et al. 2009). The translation initiation factor EIF4E binds to the cap structure at the $5^{\prime}$-end of the mRNA and favors the circularization of mRNA via the binding with EIF4G. The EIF4E-binding proteins (EIF4EBPs) such as EIF4EBP1 (Kauma 2000) inhibit the assembly of EIF4E complex but this inhibition is released after EIF4EBPs phosphorylation (Castellucci et al. 2000). Leptin also increases protein synthesis by activating the translation machinery via both PI3K and MAPK pathways (PerezPerez et al. 2009, 2010).

The balance between trophoblast proliferation and apoptosis is a mechanism to control normal trophoblast invasion (Heazell \& Crocker 2008). We have also demonstrated that leptin increases survival as well (Magarinos et al. 2007, Perez-Perez et al. 2008). Apoptosis in placental villi changes along normal pregnancy, in the first trimester is low, during the second third increases and beyond 40 weeks of gestation, it is markedly accelerated (Sharp et al. 2010).

Placental apoptosis is initiated by various stimuli, including hypoxia and oxidative stress. In trophoblast cells, apoptosis continues through the extrinsic or 
intrinsic pathways concluding in the activation of caspases. We have observed that leptin treatment in Swan-71 cells or human-term placental explants prevents early and late events of the apoptotic pathway, diminishing caspase- 3 and PARP-1 cleavage. Moreover, leptin diminished p53 both at mRNA and protein levels (Toro et al. 2014).

The p53 protein is a master cell cycle regulator that increases in response to several stress stimuli as heat shock, hypoxia, osmotic shock and DNA damage, resulting in growth arrest, apoptosis promotion and DNA repair (Prives \& Hall 1999). In injured cells, p53 is activated by phosphorylation and acetylation at multiple sites to modulate downstream target genes (Meek \& Anderson 2009). It was shown that phosphorylation of p53 at serine 46 promotes the expression of proteins like the apoptosis-inducing protein 1 (p53AIP1) which in turn trigger the apoptosis pathway (Oda et al. 2000). We have previously reported that leptin treatment in placental cells decreases serine 46 phosphorylation on p53, suggesting a pro-survival effect of this cytokine (Toro et al. 2014).

Protein levels of p53 are diminished by the activation of MDM2, an E3 ubiquitin ligase that via a negative feedback loop leads p53 to proteasome degradation (Wade et al. 2013). In addition, leptin treatment increased the MDM2 expression both in Swan-71 cells and in human-term placental explants, and concomitantly diminished p53 half-life determined by cycloheximide experiments. It was also demonstrated that leptin diminished apoptosis via MAPK pathway (Toro et al. 2015, Perez-Perez et al. 2016). Results obtained with the use of pharmacological inhibitors suggest that $\mathrm{PI} 3 \mathrm{~K}$ activation may mediate other functions of leptin in placenta, and that MAPK pathway is the principal signaling pathway that mediates the anti-apoptotic effect of leptin in placenta (Perez-Perez et al. 2008).

During a normal pregnancy, trophoblast differentiation must not only be fairly regulated in a spatial and temporal manner but also requires potent immunomodulatory strategies to prevent trophoblast rejection by maternal alloreactive lymphocytes and natural killer cells present in the decidua (PrabhuDas et al. 2015). One of these mechanisms appears to be the particular pattern of histocompatibility antigens expressed by extravillous cytotrophoblasts. They lack the polymorphic human leukocyte antigen (HLA) class la surface molecules and express instead the non-classical MHC class IB antigens (Hutter et al. 1998). Among these molecules, HLA-G generates great interest due to its immunosuppressive effects increasing apoptosis of activated $\mathrm{CD}^{+} \mathrm{T}$ lymphocytes, promoting the generation of tolerogenic antigen presenting cells and preventing NK cellmediated cytotoxicity (Persson et al. 2017). Leptin, as a pro-inflammatory cytokine, was linked to the promotion of immune escape mechanisms. Our data demonstrated a central role of leptin as a paracrine/autocrine signal enhancing trophoblast HLA-G expression (Barrientos et al. 2015). Our results place placental leptin as an endogenous regulator of the differentiation process of trophoblast cells, promoting a tolerogenic phenotype to prevent immunological damage; meanwhile, they invade maternal tissues during early stages of pregnancy.

\section{Leptin is an integrative target of different placental stimuli}

Leptin acts as an integrative cytokine between different placenta stimuli, such us growth hormones, steroid hormones, hypoxia, pro-inflammatory signals and so on.

During pregnancy, leptin levels in mother circulation are elevated, compared with those in age- and bodymass-index-matched non-pregnant women, reaching a peak in the second and third trimesters. At the end of pregnancy, circulating leptin levels decline to normal values $24 \mathrm{~h}$ after delivery (Hardie et al. 1997). The placenta is the principal source of maternalcirculating leptin. Although increased mother adiposity during pregnancy might be responsible for the hyperleptinaemia, leptin levels are elevated to an extent that cannot be explained by the increased body mass index (Hardie et al. 1997).

Deregulation of leptin function in the placenta may be implicated in the pathogenesis of various disorders during pregnancy, such as gestational diabetes, recurrent miscarriage, preeclampsia and intrauterine growth retardation (Bajoria et al. 2002, Sagawa et al. 2002). Placental leptin secretion is potentiated by IL1A and IL6 (Hardie et al. 1997, Chardonnens et al. 1999, Meissner et al. 2003, Maymo et al. 2011). It was also demonstrated that the human leptin gene is actively engaged by hypoxia through mechanisms that are common to other hypoxia-inducible genes (Ambrosini et al. 2002).

Different placental hormones enhance the leptin expression. We have demonstrated that hCG increased the leptin expression at the transcriptional level and that a minimal promoter region spanning up to $-218 \mathrm{bp}$ was enough to evidence this induction (Maymo et al. 2009).

On the other hand in cytotrophoblastic cells, leptin secretion is significantly stimulated by GnRH-II (Islami et al. 2003). It is probably that among the diverse hormones secreted by the placenta, principally during the first trimester of pregnancy, GnRH, hCG and leptin are involved in an autocrine/paracrine loop-regulating placental function.

The principal hCG function is to maintain progesterone production by corpus luteum during early pregnancy, through the stimulation of $\mathrm{LH} / \mathrm{HCG}$ receptor. Binding of hCG to its receptor activates signal transduction through the associated heterotrimeric G-proteins. Besides, hCG has many other functions, being one of the earliest embryonic signals, and is probably involved in the embryo-maternal dialog-regulating implantation (Rao 2001). 
The leptin expression is also upregulated in placental cells by estradiol (Chardonnens et al. 1999). Steroids play a fundamental role in growth and differentiation of human cells and are required for the development and maintenance of reproductive tissues (Chen et al. 2004). Human placenta synthesizes estrogens during pregnancy, in concordance with cytotrophoblast invasion.

We observed a significant upregulation of leptin expression in BeWo cells at the transcriptional level. Moreover, treatment with the antiestrogen ICI 182,780 completely blocked $E_{2}$ induction of leptin expression in human placental explants, and also repressed the basal leptin expression, suggesting a role of endogenous estradiol in the autocrine control of leptin synthesis (Gambino et al. 2010).

We have also shown that the placental leptin expression is upregulated by insulin (Perez-Perez et al. 2013). In this regard, it has been reported that insulin regulates the leptin expression both in adipose tissue and placenta. Insulin administration enhances the synthesis of leptin mRNA transcripts and protein secretion by adipocytes, in vitro (Cammisotto et al. 2006). We demonstrated that $10 \mathrm{nM}$ insulin enhances the leptin expression and is in agreement with some studies where a positive correlation between insulin and serological levels of leptin in pregnant women was found (Hardie et al. 1997, Saltiel \& Pessin 2002).

\section{Signal transduction pathways mediating leptin induction}

Increments in intracellular cAMP usually lead to the activation of cAMP-dependent protein kinase (PKA), which in turn phosphorylates intracellular substrates, including the cAMP response element-binding protein (CREB). However, several experiments have evidenced that CAMP affects some cellular processes independently on PKA (Renstrom et al. 1997, Cass et al. 1999, Staples et al. 2001). It was demonstrated that in BeWo cells and human-term placental tissue, leptin secretion is augmented by forskolin, an activator of PKA (Yura et al. 1998). On the other hand, cAMP is known to alter human trophoblast function as demonstrated in numerous in vitro studies of normal and transformed trophoblast cells (Strauss et al. 1992).

We demonstrated a significant leptin upregulation by cAMP in BeWo, JEG-3 cells and placental explants. Moreover, cAMP increased leptin promoter activity and leptin mRNA transcription (Maymo et al. 2010). The stimulatory cAMP effect on the leptin expression was also reported in several cells such as glioma cells, pituitary tumor cells (Morash et al. 2000, Li et al. 2001), breast cancer cells ( $\mathrm{O}^{\prime} \mathrm{Neil}$ et al. 2001), gastric cells (Goiot et al. 2005) and placental chorionic tissue (Yura et al. 1998).

It is known that PKA pathway activation plays an important role in biological signaling of different hormones in the placenta, such as hCG (Strauss et al. 1992). The inductive effect of cAMP on the leptin expression might result from the activation of PKA-dependent or PKA-independent events. The downregulation of leptin expression by the transfection of a dominant negative regulatory subunit of PKA (PKI) demonstrated the involvement of PKA pathway in CAMP leptin induction. Besides, specific inhibition of PKA with H89 suppressed cAMP leptin induction both in BeWo cells and in placental explants (Maymo et al. 2010). All these data suggest that cAMP stimulates the leptin expression through a PKA-dependent signaling pathway.

On the other hand, it was reported that MAPK pathway is essential for reproduction. It has been involved in oocyte maturation and in the regulation of trophoblast invasion and placental development (Hatano et al. 2003, Fitzgerald et al. 2005). It has been reported that MAPK cascade can modulate PKA activation by different mechanisms (Gerits et al. 2008). Possible crosstalk between these pathways was determined to investigate the molecular mechanisms underlying the cAMP effect on leptin upregulation in trophoblastic cells. We demonstrated that cAMP treatment specifically activated ERK $1 / 2$ phosphorylation in placental cells (Maymo et al.2010). Besides, the inhibition of PKA increases ERK phosphorylation in placenta, suggesting that cAMP might activate ERK pathway in a PKA-independent manner. Moreover, using an MEK inhibitor, PD98059 partially blocked leptin induction caused by the overexpression of the catalytic subunit of the PKA.

On the other hand, it is reported that cAMP activates MAPK through members of the Ras superfamily activating Rap1A, which then increases ERK phosphorylation (Lange-Carter et al. 1993, Kawasaki et al. 1998). Our data demonstrated that the leptin expression is induced in placenta through the cAMP/Epac alternative signaling pathway. It was seen that the overexpression of Epac and Rap1 proteins resulted in a significant increase in leptin promoter activity. Moreover, when trophoblastic cells were incubated with CPT-OMe, a cAMP analog that specifically activates Epac, the leptin expression was increased (Maymo et al. 2012). These results demonstrate that the role of cAMP as a second messenger of hCG would be PKA-independent and involves the activation of the alternative cAMP/Epac pathway.

We have also demonstrated the involvement of MAPK signaling pathway in hCG leptin upregulation both by using PD98059 and by the overexpression of a dominant negative mutant of ERK2. Moreover, hCG treatment 
specifically activates MEK and ERK1/2 phosphorylation in placental cells (Maymo et al. 2009).

Besides with gene regulation, estradiol also mediates rapid non-genomic effects (Wade et al. 2001). These actions are initiated in the cellular membrane and indirectly regulate the gene expression, through the activation of signal transduction pathways. The activation of the MAPK and PI3K signaling pathways by estradiol in different cell types has been reported (Bjornstrom \& Sjoberg 2005). Both pathways can also be activated in placental cell explants following estradiol treatment. We have previously demonstrated that the stimulatory effect of $E_{2}$ on the leptin expression was blocked by PD98059, an MAPK pharmacological inhibitor or by the overexpression of dominant negative mutant forms of MAPK, suggesting that this pathway is involved in the estradiol-induced leptin expression (Gambino et al. 2010).

The nature of the membrane receptors for estrogens is under investigation. However, $E R \alpha, E R \beta$ and nonclassical ER (e.g. ER-X and GPR30) have been identified at different target cell membranes (Acconcia \& Kumar 2006). Particularly, using the conjugated molecule estradiol-BSA, that is unable to enter the cell due to its large size, we demonstrated that estradiol regulation of leptin expression in placental cells was partially mediated by estrogen membrane receptors. The presence of ER $\alpha$ in BeWo plasmatic membranes was also demonstrated (Gambino et al. 2012b).

\section{Leptin promoter organization and transcription factors involved in its expression}

In 1995, the group of J Friedman mapped the human LEP gene in a portion of human chromosome $7 q$ (Green et al. 1995).

Later on, different regulatory elements were identified along the leptin promoter, e.g., cAMP, estrogen receptors and glucocorticoid response elements, CCATT/enhancer, Sp-1, activator protein 1 (AP1) and nuclear factor kappaB (NFkB) binding sites, among others, suggesting a complex regulation of leptin expression through different transcriptional crosstalks (Zhang et al. 1994, He et al. 1995, Isse et al. 1995, Gong et al. 1996). A specific placental enhancer located 1.9-kb upstream the human leptin gene was identified. It is active in choriocarcinoma lines but not in adipose cells (Bi et al. 1997). Given the importance of leptin regulation during pregnancy, it is expected that different transcription factors participate in concert to modulate the leptin expression in placenta. In Fig. 1, a schematic representation of in silico analysis of leptin promoter can be observed. The cartoon shows both confirmed and putative binding sites to the main transcription factors regulating the leptin expression in the placenta.

In silico analysis of leptin promoter fragment showed consensus elements for different potential transcription factors such as C/EBP and Sp1 with a core similarity of 1, cAMP response elements (CRE) and estrogen

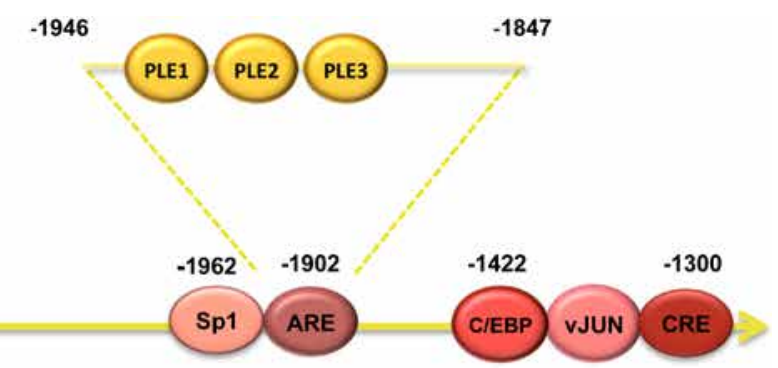

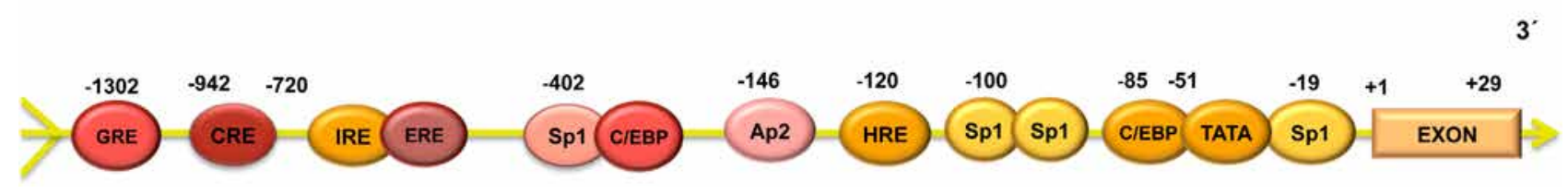

Figure 1 Leptin promoter element analysis. The schematic cartoon shows reported and putative regulatory elements for different transcription factors. The enlargement of the promoter region shows the positions of the placental leptin enhancer (PLE 1, 2 and 3). In silico analysis to identify putative elements was performed with the MatInspector Release Professional 8.0.3 program. Ap2, activating protein 2; ARE, androgens response elements; C/EBP, CCAAT/enhancer-binding protein; CRE, CAMP response element-binding protein; ERE, estrogens response element; HRE, hypoxia response element; GRE, glucocorticoid response element; IRE, insulin response element; NFkB, nuclear factor kappaB; Sp1, stimulant protein 1. 
receptor binding sites (ERE), among others. Previous data have demonstrated the involvement of both C/EBP and Sp1 transcription factors in the regulation of leptin gene in adipocytes (Mason et al. 1998). Moreover, the C/EBP transcription factor expression was reported to be regulated by hCG in the follicular development (Sirois \& Richards 1993), in rat primary cultures of Leydig cells and in human adipose cells (Nalbant et al. 1998, Dos Santos et al. 2007).

Estrogen, acting through the activation of $E R \alpha$ or $E R \beta$, regulates gene expression through different mechanisms. The classical pathway involves ligand-bound receptor binding at a specific palindromic sequence of DNA (ERE) within the promoters of estrogen-responsive genes (Beato et al. 1995). Nevertheless, genomic effects of estrogen can also proceed through ERE-independent mechanism, involving protein-protein interactions with other transcription factors.

Ligand-bound ER mediates gene transcription from AP1 enhancer elements, when binds with AP1 transcription factors FOS and JUN (Gaub et al. 1990, Weisz \& Rosales 1990, Umayahara et al. 1994). It was also reported that genes containing GC-rich sequences in their promoters are regulated through the interaction of ERs with Sp1 transcription factor (Porter et al. 1997).

Our results support the participation of ER $\alpha$ in $\mathrm{E}_{2}$-induced placental leptin expression and demonstrated that a minimal region encompassed between $-1951 \mathrm{bp}$ and $-1847 \mathrm{bp}$ is sufficient to evidence such induction. Moreover, using in silico analysis, we have found that this promoter fragment contains potential consensus halfsites for ERE, a putative binding site for Sp1 transcription factor and a placental enhancer region, PLE, previously described by Gavrilova and collaborators (Bi et al. 1997, Gambino et al. 2012a).

It was reported that genes containing GC-rich promoter sequences are regulated in a similar manner through the interaction of ERs with the Sp1 transcription factor (Safe \& Kim 2008). Sp1 transcription factor binds the consensus binding site with variable affinities. Previous reports demonstrated the involvement of Sp1 in the modulation of leptin expression in adipocytes (Mason et al. 1998).

The overexpression of Sp1 transcription factor on the leptin expression was analyzed in BeWo cells. A significant upregulation was observed. Moreover, estradiol treatment exerted a synergistic effect on Sp1 induction of leptin expression. This effect was dependent on the integrity of the Sp1 binding site, as the estradiol effect was abolished when testing a construction containing a mutated Sp1 binding site and these results suggest a crosstalk between Sp1 and ERs (Schanton et al. 2017). These results are shown in Fig. 2. ER and Sp1 transcription factors interact and form a protein-protein complex in the absence of DNA. It was observed that the DNA-binding domain deletion of ER does not prevent
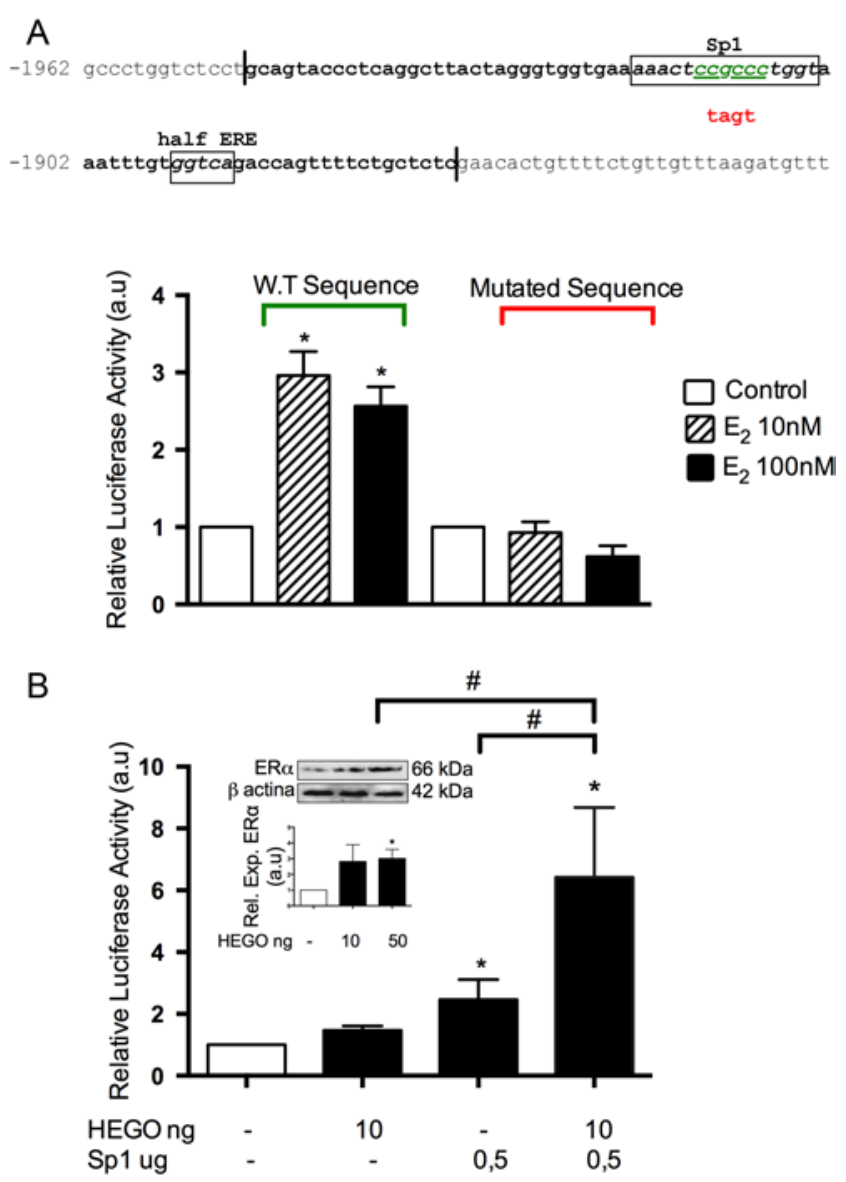

Figure $2 \mathrm{Sp} 1$ is a modulator of estradiol leptin induction in placental cells. (A) Leptin promoter sequence $(-2922$ to +29$)$ was analyzed by the MatInspector 7.7.3. The enhancer element of placental leptin (PLE) is indicated in bold text and contains the elements related to the action of $E_{2}$ : Sp1 binding site and half ERE are indicated in black boxes. The mutated Sp1 binding site is indicated below the Sp1 box in red. BeWo cells were transiently transfected with the plasmid wild type, and with the mutated plasmid (leptin promoter region from -1951 to $1887 \mathrm{bp}$, with a mutation in the Sp1 binding site), and treated with $\mathrm{E}_{2}$ as indicated during $48 \mathrm{~h}$ in DMEM-F12 media supplemented with $1 \%$ FBS. Luc activity was measured in cellular extracts and normalized to $\beta$-galactosidase activity $(n=3)$. Statistical analyses were performed by ANOVA followed by Dunnett's post hoc test vs control. a.u., arbitrary units. (B) BeWo cells were transiently transfected with plasmid construction containing the promoter region of leptin gene from -1951 to $-1847 \mathrm{bp}$ and different amounts of plasmid expressing human ER $\alpha$ (HEGO) and Sp1 expression plasmid. After transfection, BeWo cells were incubated for $48 \mathrm{~h}$ in DMEM-F12 media supplemented with $1 \%$ FBS. Luc activity was measured in cellular extracts and normalized to $\beta$-galactosidase activity $(n=3)$. Statistical analyses were performed by ANOVA followed by the Bonferroni post hoc test ${ }^{*} P<0.05$, vs control, and ${ }^{\sharp} P<0.05$ between treatments. The inset figure shows BeWo cells transiently transfected with different concentrations of the plasmid HEGO. ER $\alpha$ was determined by Western blot. Loading controls were performed by immunoblotting the same membrane with anti- $\beta$-actin as indicated. Band densitometry is shown in the lower panel $(n=3)$. Statistical analyses were performed by ANOVA follow by the Dunnett post hoc test. $* P<0.05$. 
the synergy of the ER with Sp1, suggesting that ERs can regulate transcription in the absence of a functional ERE (Porter et al. 1997). It was reported that ER $\alpha$ preferentially binds to the C-terminal DNA-binding domain of Sp1 protein (Safe 2001). Moreover, it was demonstrated that the binding of ER to Sp1 protein increases Sp1-DNA binding to EREs independently of estrogen, although the transactivation of the gene is enhanced in the presence of the ligand (Porter et al. 1997).

We showed data which demonstrate that the overexpression of $E R \alpha$ in BeWo cells synergistically increased Sp1-induced leptin expression. Moreover, this enhancement was not further augmented by estradiol treatment, suggesting a ligand independent effect. These results are in concordance with reported data which showed that the interaction of ER and Sp1 proteins was observed in the presence or absence of E2 and therefore was hormone-independent (Porter et al. 1997).

In previous reports, we have determined that cells with decreased expression of ER $\alpha$ through a specific siRNA completely prevented the effect of Sp1 on the leptin expression. On the other hand when using a construct with a mutated Sp1 binding site and intact $E R E$, the $E R \alpha$-enhanced leptin transcriptional activity was abolished, demonstrating that the Sp1 binding site contributes to ER signaling.

According to the 'Classical genomic model', ligand-activated ERs bind to specific ERE to modulate transcriptional activity of estrogen target genes. Nevertheless, $35 \%$ of the categorized human estrogenresponsive genes are expressed via indirect ER-DNA association and require protein-protein interactions with several transcription factors such as Sp1, NF-kB orAP1 (O'Connor et al. 2016). Regarding the involvement of NF-kB transcription factor on the leptin expression, unpublished results from our group showed that p65 subunit is entering the nucleus after estradiol treatment and enhances leptin transcription.

Stress is normal during early embryogenesis and during the peri-implantation, embryo is the result of maternal hormones, like leptin, that signal and prepare the new organism for development and implantation. Stress response mechanisms ensure that stem cells in the early embryo and placenta survive and include a small set of stress enzymes like protein kinases that hierarchically regulate nuclear function by modifying transcription factor activity. The transcription factors that are important in the stress response are JunC, JunB, HIFs and NFkB (Puscheck et al. 2015). The interaction of leptin, stress enzymes and transcription factors as $\mathrm{NF \kappa B}$ in the early embryo and placenta are a continuing central focus of research.

Among PKA intracellular substrates, the CREB transcription factor is one of the most important in regulating the expression of many cAMP-responsive genes in different cell types and in response to several signals (Mukherjee et al. 1996). When cAMP concentration rises, it is able to induce CREB phosphorylation not only in choriocarcinoma cells but also in placental explants. Moreover, the overexpression of the catalytic subunit of PKA or the transcription factor CREB exerted an upregulation of leptin promoter activity in a dose-dependent manner (Maymo et al. 2010).

On the other hand, the inhibition of MAPK pathway partially blocks CAMP-induced CREB phosphorylation. Initially, the phosphorylation of CREB at serine 133 was attributed exclusively to PKA. However, several studies have demonstrated that other kinases may phosphorylate CREB at the same residue. For example, while ERK 1/2 does not phosphorylate CREB directly, it can activate members of the pp90rsk family of protein kinases (RSK13 ), which, in response, translocate into the nucleus and phosphorylate CREB (Shaywitz \& Greenberg 1999).

Estradiol leptin induction in BeWo cells is dependent on the integrity of the PKA signaling. Unpublished results showed that the inhibition of adenylyl cyclase or PKA activities with H89 or SQ22,536, respectively, diminished estradiol effect on the leptin placental expression. On the other hand, the overexpression of the coactivator and acetyltransferase protein CBP enhances estradiol leptin induction, while the overexpression of the histone deacetylase HDAC generates the opposite effect. These results suggest a crosstalk between estradiol and PKA signaling probably involving the acetylation modification of histones present in the leptin promoter regions. In concordance with this hypothesis, it was reported that blocking PKA activation with H89 abrogated the estradiol-induced neuroprogesterone synthesis (Bouskine et al. 2008). In Fig. 3, a representative cartoon shows the signal transduction pathways and transcription factors mediating leptin induction in placental cells discussed in previous sections.

\section{Epigenetic regulation of leptin and its consequences on fetal programming}

Increasing evidence suggests that the developmental origins of health and disease are dependent on the intrauterine environment and these conditions correlate with the offspring's risk of different metabolic diseases in adult life (Waterland \& Michels 2007). Epigenetic marks have been proposed as a mechanism for this developmental programming as they respond to diverse environmental stimuli, and are also stable during the mitosis (Jaenisch \& Bird 2003). The placenta, a metabolically active organ that regulates intrauterine environment, is crucial for fetal growth and development (Sferruzzi-Perri \& Camm 2016). DNA methylation is an epigenetic modification that involves the addition of methyl group to a cytosine base in the context of a CpG dinucleotide, usually clustered in high density in gene promoters and associated with a decreased expression (Jones 2012). DNA methylation marks are reset during embryonic development, and are then crucial in 


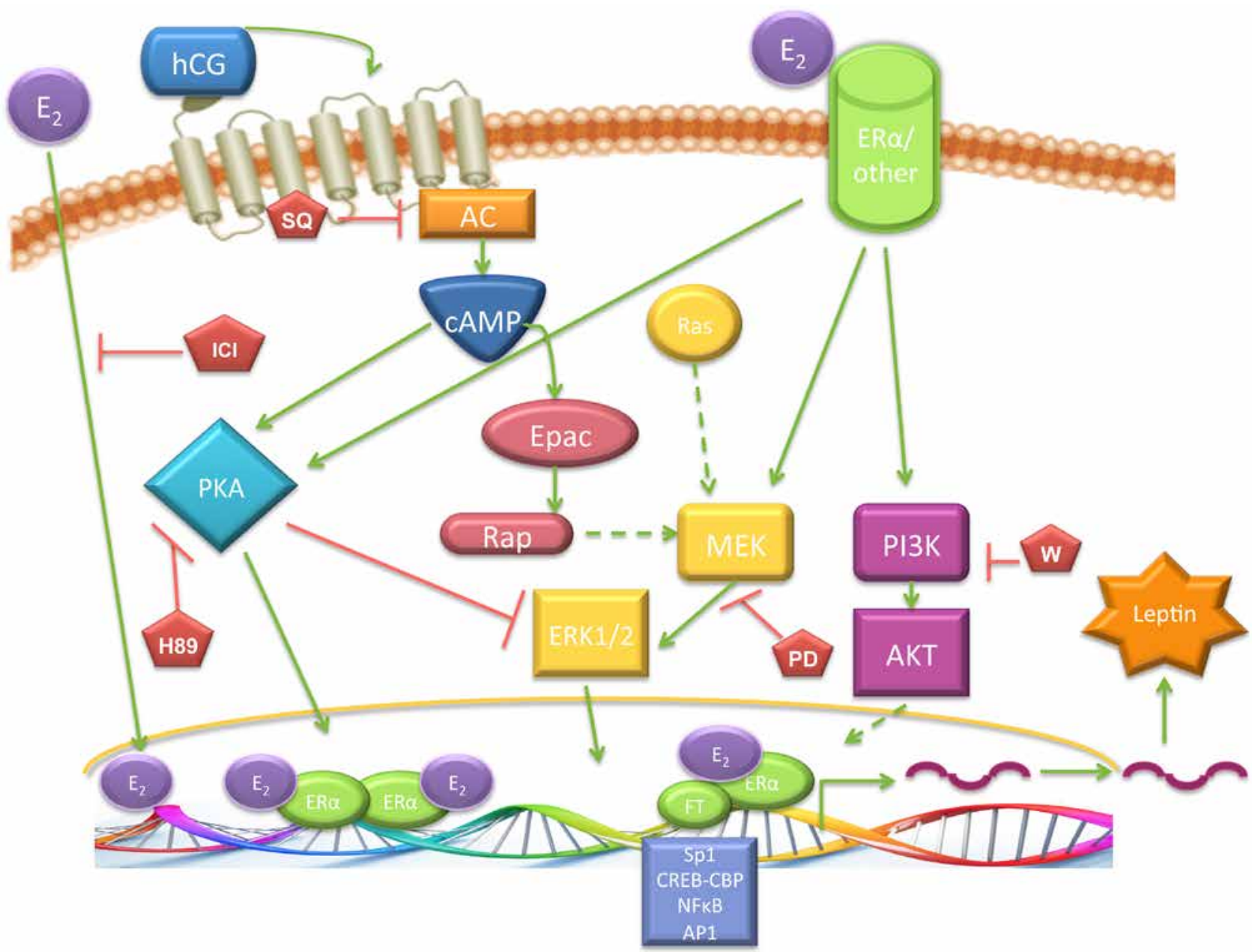

Figure 3 Signal transduction pathways and transcription factors mediating leptin induction. The proposed model shows hCG and ER $\alpha$ mechanisms involved on leptin-induced expression based on current data. hCG stimulates the leptin expression in placenta mainly by the MAPK pathway. ER $\alpha$ directly or through the interaction with different transcription factors may mediate estradiol action on the leptin expression. PKA, protein kinase A; cAMP, cyclic adenosine-3',5'-monophosphate; MAPK, mitogen-activated protein kinase; MEK, extracellular-signal regulated kinase; ERK1/2, extracellular-signal regulated kinase1/2; PI3K, phosphoinositol-3-kinase; hCG, human chorionic gonadotropin; CREB, element-binding protein; CBP, CREB bond protein; $\mathrm{E}_{2}$, estradiol; AC, adenylate cyclase; AKT, protein kinase B; NFkB, nuclear factor kappaB; Sp1, stimulant protein 1; ICI, ICl 182,780; PD, PD98059 inhibitor; W, wortmannin H89: PKA inhibitor; SQ, SQ22,536 adenylyl cyclase inhibitor. Open arrows indicate stimulation; flat arrows, inhibition.

establishing cellular differentiation pathways through their restitution in a tissue-specific manner (Novakovic \& Saffery 2012).

As discussed earlier during pregnancy, leptin in serum is produced by fetal and maternal adipose tissues and placentas (Tessier et al. 2013). It was reported that the leptin gene expression is inversely correlated with promoter DNA methylation (Bouchard etal. 2010) and has been proposed as a mediator of metabolic programming (Vickers \& Sloboda 2012). Moreover, if the methylation level in fetal or placental leptin promoter is changed during pregnancy, fetal development may be affected. Previous studies have shown that the fetal methylation level of leptin could be affected by the intrauterine environment (Briffa et al. 2015). It was reported that gestational high-fat diet decreases promoter methylation of leptin in the offspring (Khalyfa et al. 2013). In humans, the concentration of circulating leptin is altered by obesity and the promoter methylation of leptin is also altered in obese individuals (Garcia-Cardona et al. 2014). Moreover, previous published results suggest that the maternal metabolic status before and during pregnancy can alter placental $L E P$ DNA methylation profile at birth and might contribute to metabolic programming of obesity and related conditions (Lesseur et al. 2014b).

It was reported that placental $L E P$ promoter methylation is accompanied by pregnancy complications such as impaired glucose metabolism (Bouchard et al. 2010) and early onset preeclampsia (Hogg et al. 2013).

It was also demonstrated that $L E P$ DNA methylation is associated with maternal pre-pregnancy obesity and pregnancy smoking and infant factors like small 
for gestational age and genotype in non-pathological pregnancies (Lesseur et al. 2013). The same group has found evidence of a placental LEP DNA methylation and profiles of male infant neurobehavior with distinct motor disabilities (Lesseur et al. 2014a).

In conclusion, leptin may be considered a key regulator of placental physiology.

\section{Declaration of interest}

The authors declare that there is no conflict of interest that could be perceived as prejudicing the impartiality of this review.

\section{Funding}

This work was supported by the Universidad de Buenos Aires (UBACYT 2012-2015-20020110100022), the ANPCyT (PICT 2012-1366), the CONICET (PIP 11220130100217 CO), Argentina, and the Spanish Grant from ISCIII (PI09/00119 and PI12/01172), cofunded in part by FEDER, Spain.

\section{References}

Acconcia F \& Kumar R 2006 Signaling regulation of genomic and nongenomic functions of estrogen receptors. Cancer Letters 238 1-14. (doi:10.1016/j.canlet.2005.06.018)

Achache H \& Revel A 2006 Endometrial receptivity markers, the journey to successful embryo implantation. Human Reproduction Update $\mathbf{1 2}$ 731-746. (doi:10.1093/humupd/dml004)

Ambrosini G, Nath AK, Sierra-Honigmann MR \& Flores-Riveros J 2002 Transcriptional activation of the human leptin gene in response to hypoxia. Involvement of hypoxia-inducible factor 1. Journal of Biological Chemistry 277 34601-34609. (doi:10.1074/jbc.M205172200)

Aplin JD 2000 The cell biological basis of human implantation. Bailliere's Best Practice and Research: Clinical Obstetrics and Gynaecology $\mathbf{1 4}$ 757-764. (doi:10.1053/beog.2000.0116)

Bajoria R, Sooranna SR, Ward BS \& Chatterjee R 2002 Prospective function of placental leptin at maternal-fetal interface. Placenta 23 103-115. (doi:10.1053/plac.2001.0769)

Barrientos G, Toro A, Moschansky P, Cohen M, Garcia MG, Rose M, Maskin B, Sanchez-Margalet V, Blois SM \& Varone CL 2015 Leptin promotes HLA-G expression on placental trophoblasts via the MEK/ Erk and PI3K signaling pathways. Placenta 36 419-426. (doi:10.1016/j. placenta.2015.01.006)

Beato M, Herrlich P \& Schutz G 1995 Steroid hormone receptors: many actors in search of a plot. Cell 83 851-857. (doi:10.1016/00928674(95)90201-5)

Bi S, Gavrilova O, Gong DW, Mason MM \& Reitman M 1997 Identification of a placental enhancer for the human leptin gene. Journal of Biological Chemistry 272 30583-30588. (doi:10.1074/jbc.272.48.30583)

Bjorbaek C, Buchholz RM, Davis SM, Bates SH, Pierroz DD, Gu H, Neel BG, Myers MG Jr \& Flier JS 2001 Divergent roles of SHP-2 in ERK activation by leptin receptors. Journal of Biological Chemistry 276 4747-4755. (doi:10.1074/jbc.M007439200)

Bjornstrom L \& Sjoberg M 2005 Mechanisms of estrogen receptor signaling: convergence of genomic and nongenomic actions on target genes. Molecular Endocrinology 19 833-842. (doi:10.1210/me.20040486)

Bouchard L, Thibault S, Guay SP, Santure M, Monpetit A, St-Pierre J, Perron P \& Brisson D 2010 Leptin gene epigenetic adaptation to impaired glucose metabolism during pregnancy. Diabetes Care 33 2436-2441. (doi:10.2337/dc10-1024)

Bouskine A, Nebout M, Mograbi B, Brucker-Davis F, Roger C \& Fenichel P 2008 Estrogens promote human testicular germ cell cancer through a membrane-mediated activation of extracellular regulated kinase and protein kinase A. Endocrinology 149 565-573. (doi:10.1210/en.20071318)

Briffa JF, McAinch AJ, Romano T, Wlodek ME \& Hryciw DH 2015 Leptin in pregnancy and development: a contributor to adulthood disease? American Journal of Physiology: Endocrinology and Metabolism 308 E335-E350. (doi:10.1152/ajpendo.00312.2014)

Cameo P, Bischof P \& Calvo JC 2003 Effect of leptin on progesterone, human chorionic gonadotropin, and interleukin- 6 secretion by human term trophoblast cells in culture. Biology of Reproduction 68 472-477. (doi:10.1095/biolreprod.102.006122)

Cammisotto PG, Bukowiecki LJ, Deshaies Y \& Bendayan M 2006 Leptin biosynthetic pathway in white adipocytes. Biochemistry and Cell Biology 84 207-214. (doi:10.1139/o06-032)

Carson DD, Bagchi I, Dey SK, Enders AC, Fazleabas AT, Lessey BA \& Yoshinaga K 2000 Embryo implantation. Developmental Biology 223 217-237. (doi:10.1006/dbio.2000.9767)

Cass LA, Summers SA, Prendergast GV, Backer JM, Birnbaum MJ \& Meinkoth JL 1999 Protein kinase A-dependent and -independent signaling pathways contribute to cyclic AMP-stimulated proliferation. Molecular and Cellular Biology 19 5882-5891. (doi:10.1128/ MCB.19.9.5882)

Castellucci M, De Matteis R, Meisser A, Cancello R, Monsurro V, Islami D, Sarzani R, Marzioni D, Cinti S \& Bischof P 2000 Leptin modulates extracellular matrix molecules and metalloproteinases: possible implications for trophoblast invasion. Molecular Human Reproduction 6 951-958. (doi:10.1093/molehr/6.10.951)

Cervero A, Horcajadas JA, MartIn J, Pellicer A \& Simon C 2004 The leptin system during human endometrial receptivity and preimplantation development. Journal of Clinical Endocrinology and Metabolism 89 2442-2451. (doi:10.1210/jc.2003-032127)

Cervero A, Horcajadas JA, Dominguez F, Pellicer A \& Simon C 2005 Leptin system in embryo development and implantation: a protein in search of a function. Reproductive BioMedicine Online 10 217-223. (doi:10.1016/ S1472-6483(10)60943-1)

Corvinus FM, Fitzgerald JS, Friedrich K \& Markert UR 2003 Evidence for a correlation between trophoblast invasiveness and STAT3 activity. American Journal of Reproductive Immunology 50 316-321. (doi:10.1034/j.1600-0897.2003.00099.x)

Coya R, Martul P, Algorta J, Aniel-Quiroga MA, Busturia MA \& Senaris R 2006 Effect of leptin on the regulation of placental hormone secretion in cultured human placental cells. Gynecological Endocrinology 22 620-626. (doi:10.1080/09513590601012587)

Chardonnens D, Cameo P, Aubert ML, Pralong FP, Islami D, Campana A, Gaillard RC \& Bischof P 1999 Modulation of human cytotrophoblastic leptin secretion by interleukin-1alpha and 17beta-oestradiol and its effect on HCG secretion. Molecular Human Reproduction 5 1077-1082. (doi:10.1093/molehr/5.11.1077)

Chen Z, Katzenellenbogen BS, Katzenellenbogen JA \& Zhao H 2004 Directed evolution of human estrogen receptor variants with significantly enhanced androgen specificity and affinity. Journal of Biological Chemistry 279 33855-33864. (doi:10.1074/jbc.M402118200)

Dos Santos E, Dieudonne MN, Leneveu MC, Pecquery R, Serazin V \& Giudicelli Y 2007 In vitro effects of chorionic gonadotropin hormone on human adipose development. Journal of Endocrinology 194 313-325. (doi:10.1677/JOE-06-0101)

Dos Santos E, Duval F, Vialard F \& Dieudonne MN 2015 The roles of leptin and adiponectin at the fetal-maternal interface in humans. Hormone Molecular Biology and Clinical Investigation 24 47-63. (doi:10.1515/ hmbci-2015-0031)

Fitzgerald JS, Busch S, Wengenmayer T, Foerster K, de la Motte T, Poehlmann TG \& Markert UR 2005 Signal transduction in trophoblast invasion. Chemical Immunology and Allergy 88 181-199.

Flier JS 1995 The adipocyte: storage depot or node on the energy information superhighway? Cell 80 15-18. (doi:10.1016/0092-8674(95)90445-X)

Gambino YP, Maymo JL, Perez-Perez A, Duenas JL, SanchezMargalet V, Calvo JC \& Varone CL 2010 17Beta-estradiol enhances leptin expression in human placental cells through genomic and nongenomic actions. Biology of Reproduction 83 42-51. (doi:10.1095/ biolreprod.110.083535)

Gambino YP, Maymo JL, Perez Perez A, Calvo JC, Sanchez-Margalet V \& Varone CL 2012a Elsevier trophoblast research award lecture: molecular mechanisms underlying estrogen functions in trophoblastic cells - focus 
on leptin expression. Placenta 33 (Supplement) S63-S70. (doi:10.1016/j. placenta.2011.12.001)

Gambino YP, Perez Perez A, Duenas JL, Calvo JC, Sanchez-Margalet V \& Varone CL 2012b Regulation of leptin expression by 17 beta-estradiol in human placental cells involves membrane associated estrogen receptor alpha. Biochimica et Biophysica Acta 1823 900-910. (doi:10.1016/j. bbamcr.2012.01.015)

Garcia-Cardona MC, Huang F, Garcia-Vivas JM, Lopez-Camarillo C, Del Rio Navarro BE, Navarro Olivos E, Hong-Chong E, Bolanos-Jimenez F \& Marchat LA 2014 DNA methylation of leptin and adiponectin promoters in children is reduced by the combined presence of obesity and insulin resistance. International Journal of Obesity 38 1457-1465. (doi:10.1038/ ijo.2014.30)

Gaub MP, Bellard M, Scheuer I, Chambon P \& Sassone-Corsi P 1990 Activation of the ovalbumin gene by the estrogen receptor involves the fos-jun complex. Cell 63 1267-1276. (doi:10.1016/00928674(90)90422-B)

Gerits N, Kostenko S, Shiryaev A, Johannessen M \& Moens U 2008 Relations between the mitogen-activated protein kinase and the cAMPdependent protein kinase pathways: comradeship and hostility. Cell Signaling 20 1592-1607. (doi:10.1016/j.cellsig.2008.02.022)

Goiot H, Laigneau JP, Devaud H, Sobhani I \& Bado A 2005 Similarities and differences in the transcriptional regulation of the leptin gene promoter in gastric and adipose cells. FEBS Letters 579 1911-1916. (doi:10.1016/j. febslet.2005.02.031)

Gong DW, Bi S, Pratley RE \& Weintraub BD 1996 Genomic structure and promoter analysis of the human obese gene. Journal of Biological Chemistry 271 3971-3974. (doi:10.1074/jbc.271.8.3971)

Gorska E, Popko K, Stelmaszczyk-Emmel A, Ciepiela O, Kucharska A \& Wasik M 2010 Leptin receptors. European Journal of Medical Research 15 (Supplement 2) 50-54. (doi:10.1186/2047-783X-15-S2-50)

Green ED, Maffei M, Braden VV, Proenca R, DeSilva U, Zhang Y, Chua SC Jr, Leibel RL, Weissenbach J \& Friedman JM 1995 The human obese (OB) gene: RNA expression pattern and mapping on the physical, cytogenetic, and genetic maps of chromosome 7. Genome Research $\mathbf{5}$ 5-12. (doi:10.1101/gr.5.1.5)

Hardie L, Trayhurn P, Abramovich D \& Fowler P 1997 Circulating leptin in women: a longitudinal study in the menstrual cycle and during pregnancy. Clinical Endocrinology 47 101-106. (doi:10.1046/j.13652265.1997.2441017.x)

Hatano N, Mori Y, Oh-hora M, Kosugi A, Fujikawa T, Nakai N, Niwa H, Miyazaki J, Hamaoka T \& Ogata M 2003 Essential role for ERK2 mitogen-activated protein kinase in placental development. Genes to Cells 8 847-856. (doi:10.1046/j.1365-2443.2003.00680.x)

He Y, Chen H, Quon MJ \& Reitman M 1995 The mouse obese gene. Genomic organization, promoter activity, and activation by CCAAT/ enhancer-binding protein alpha. Journal of Biological Chemistry 270 28887-28891. (doi:10.1074/jbc.270.48.28887)

Heazell AE \& Crocker IP 2008 Live and let die - regulation of villous trophoblast apoptosis in normal and abnormal pregnancies. Placenta $\mathbf{2 9}$ 772-783. (doi:10.1016/j.placenta.2008.07.003)

Henson MC \& Castracane VD 2006 Leptin in pregnancy: an update. Biology of Reproduction 74 218-229. (doi:10.1095/biolreprod.105.045120)

Hogg K, Blair JD, von Dadelszen P \& Robinson WP 2013 Hypomethylation of the LEP gene in placenta and elevated maternal leptin concentration in early onset pre-eclampsia. Molecular and Cellular Endocrinology 367 64-73. (doi:10.1016/j.mce.2012.12.018)

Hohos NM \& Skaznik-Wikiel ME 2017 High fat diet and female fertility. Endocrinology 158 2407-2419. (doi:10.1210/en.2017-00371)

Houseknecht KL \& Portocarrero CP 1998 Leptin and its receptors: regulators of whole-body energy homeostasis. Domestic Animal Endocrinology 15 457-475. (doi:10.1016/S0739-7240(98)00035-6)

Hutter H, Hammer A, Dohr G \& Hunt JS 1998 HLA expression at the maternal-fetal interface. Developmental Immunology 6 197-204. (doi:10.1155/1998/65065)

Islami D, Bischof P \& Chardonnens D 2003 Possible interactions between leptin, gonadotrophin-releasing hormone (GnRH-I and II) and human chorionic gonadotrophin (hCG). European Journal of Obstetrics, Gynecology, and Reproductive Biology 110 169-175. (doi:10.1016/ S0301-2115(03)00185-4)

Israel D \& Chua S Jr 2010 Leptin receptor modulation of adiposity and fertility. Trends in Endocrinology and Metabolism 21 10-16. (doi:10.1016/j.tem.2009.07.004)
Isse N, Ogawa Y, Tamura N, Masuzaki H, Mori K, Okazaki T, Satoh N, Shigemoto M, Yoshimasa Y, Nishi S et al. 1995 Structural organization and chromosomal assignment of the human obese gene. Journal of Biological Chemistry 270 27728-27733. (doi:10.1074/jbc.270.46.27728)

Jaenisch R \& Bird A 2003 Epigenetic regulation of gene expression: how the genome integrates intrinsic and environmental signals. Nature Genetics 33 (Supplement) 245-254. (doi:10.1038/ng1089)

Jones PA 2012 Functions of DNA methylation: islands, start sites, gene bodies and beyond. Nature Reviews Genetics 13 484-492. (doi:10.1038/ nrg3230)

Kauma SW 2000 Cytokines in implantation. Journal of Reproduction and Fertility Supplement 55 31-42.

Kawasaki H, Springett GM, Mochizuki N, Toki S, Nakaya M, Matsuda M, Housman DE \& Graybiel AM 1998 A family of cAMP-binding proteins that directly activate Rap1. Science 282 2275-2279. (doi:10.1126/ science.282.5397.2275)

Khalyfa A, Carreras A, Hakim F, Cunningham JM, Wang Y \& Gozal D 2013 Effects of late gestational high-fat diet on body weight, metabolic regulation and adipokine expression in offspring. International Journal of Obesity 37 1481-1489. (doi:10.1038/ijo.2013.12)

Lange-Carter CA, Pleiman CM, Gardner AM, Blumer KJ \& Johnson GL 1993 A divergence in the MAP kinase regulatory network defined by MEK kinase and Raf. Science 260 315-319. (doi:10.1126/science.8385802)

Lesseur C, Armstrong DA, Paquette AG, Koestler DC, Padbury JF \& Marsit CJ 2013 Tissue-specific leptin promoter DNA methylation is associated with maternal and infant perinatal factors. Molecular and Cellular Endocrinology 381 160-167. (doi:10.1016/j.mce.2013.07.024)

Lesseur C, Armstrong DA, Murphy MA, Appleton AA, Koestler DC, Paquette AG, Lester BM \& Marsit CJ 2014a Sex-specific associations between placental leptin promoter DNA methylation and infant neurobehavior. Psychoneuroendocrinology 40 1-9. (doi:10.1016/j. psyneuen.2013.10.012)

Lesseur C, Armstrong DA, Paquette AG, Li Z, Padbury JF \& Marsit CJ 2014b Maternal obesity and gestational diabetes are associated with placental leptin DNA methylation. American Journal of Obstetrics and Gynecology 211 654.e651-654.e659. (doi:10.1016/j.ajog.2014.06.037)

Li AW, Morash B, Hollenberg AN, Ur E, Wilkinson M \& Murphy PR 2001 Transcriptional regulation of the leptin gene promoter in rat $\mathrm{GH} 3$ pituitary and C6 glioma cells. Molecular and Cellular Endocrinology 176 57-65. (doi:10.1016/S0303-7207(01)00476-2)

Madej T, Boguski MS \& Bryant SH 1995 Threading analysis suggests that the obese gene product may be a helical cytokine. FEBS Letters 373 13-18. (doi:10.1016/0014-5793(95)00977-H)

Magarinos MP, Sanchez-Margalet V, Kotler M, Calvo JC \& Varone CL 2007 Leptin promotes cell proliferation and survival of trophoblastic cells. Biology of Reproduction 76 203-210. (doi:10.1095/ biolreprod.106.051391)

Martin-Romero C \& Sanchez-Margalet V 2001 Human leptin activates PI3K and MAPK pathways in human peripheral blood mononuclear cells: possible role of Sam68. Cellular Immunology 212 83-91. (doi:10.1006/ cimm.2001.1851)

Mason MM, He Y, Chen H, Quon MJ \& Reitman M 1998 Regulation of leptin promoter function by Sp1, C/EBP, and a novel factor. Endocrinology 139 1013-1022. (doi:10.1210/endo.139.3.5792)

Masuzaki H, Ogawa Y, Sagawa N, Hosoda K, Matsumoto T, Mise H, Nishimura H, Yoshimasa Y, Tanaka I, Mori T et al. 1997 Nonadipose tissue production of leptin: leptin as a novel placenta-derived hormone in humans. Nature Medicine 3 1029-1033. (doi:10.1038/nm0997-1029)

Maymo JL, Perez Perez A, Sanchez-Margalet V, Duenas JL, Calvo JC \& Varone CL 2009 Up-regulation of placental leptin by human chorionic gonadotropin. Endocrinology 150 304-313. (doi:10.1210/en.20080522)

Maymo JL, Perez Perez A, Duenas JL, Calvo JC, Sanchez-Margalet V \& Varone CL 2010 Regulation of placental leptin expression by cyclic adenosine $5^{\prime}$-monophosphate involves cross talk between protein kinase $\mathrm{A}$ and mitogen-activated protein kinase signaling pathways. Endocrinology 151 3738-3751. (doi:10.1210/en.2010-0064)

Maymó JL, Perez Perez A, Gambino Y, Calvo JC, Sánchez-Margalet V \& Varone CL 2011 Review: Leptin gene expression in the placenta regulation of a key hormone in trophoblast proliferation and survival. Placenta 32 (Supplement 2) S146-S153. (doi:10.1016/j.placenta.2011.01.004)

Maymo JL, Perez Perez A, Maskin B, Duenas JL, Calvo JC, Sanchez Margalet V \& Varone CL 2012 The alternative Epac/cAMP pathway and 
the MAPK pathway mediate hCG induction of leptin in placental cells. PLOS ONE 7 e46216. (doi:10.1371/journal.pone.0046216)

Meek DW \& Anderson CW 2009 Posttranslational modification of p53: cooperative integrators of function. Cold Spring Harbor Perspectives in Biology 1 a000950. (doi:10.1101/cshperspect.a000950)

Meissner U, Ostreicher I, Allabauer I, Rascher W \& Dotsch J 2003 Synergistic effects of hypoxia and insulin are regulated by different transcriptional elements of the human leptin promoter. Biochemical and Biophysical Research Communications 303 707-712. (doi:10.1016/ S0006-291X(03)00401-7)

Morash B, Johnstone J, Leopold C, Li A, Murphy P, Ur E \& Wilkinson M 2000 The regulation of leptin gene expression in the C6 glioblastoma cell line. Molecular and Cellular Endocrinology 165 97-105. (doi:10.1016/ S0303-7207(00)00259-8)

Mukherjee A, Park-Sarge OK \& Mayo KE 1996 Gonadotropins induce rapid phosphorylation of the $3^{\prime}, 5^{\prime}$-cyclic adenosine monophosphate response element binding protein in ovarian granulosa cells. Endocrinology 137 3234-3245. (doi:10.1210/endo.137.8.8754745)

Nalbant D, Williams SC, Stocco DM \& Khan SA 1998 Luteinizing hormone-dependent gene regulation in Leydig cells may be mediated by CCAAT/enhancer-binding protein-beta. Endocrinology 139 272-279. (doi:10.1210/endo.139.1.5663)

Novakovic B \& Saffery R 2012 The ever growing complexity of placental epigenetics - role in adverse pregnancy outcomes and fetal programming. Placenta 33 959-970. (doi:10.1016/j.placenta.2012.10.003)

O'Connor L, Gilmour J \& Bonifer C 2016 The role of the ubiquitously expressed transcription factor Sp1 in tissue-specific transcriptional regulation and in disease. Yale Journal of Biology and Medicine 89 513-525

O'Neil JS, Green AE, Edwards DE, Swan KF, Gimpel T, Castracane VD \& Henson MC 2001 Regulation of leptin and leptin receptor in baboon pregnancy: effects of advancing gestation and fetectomy. Journal of Clinical Endocrinology and Metabolism 86 2518-2524. (doi:10.1210/ jcem.86.6.7588)

Oda K, Arakawa H, Tanaka T, Matsuda K, Tanikawa C, Mori T, Nishimori H, Tamai K, Tokino T, Nakamura Y et al. 2000 p53AIP1, a potential mediator of p53-dependent apoptosis, and its regulation by Ser-46-phosphorylated p53. Cell 102 849-862. (doi:10.1016/S00928674(00)00073-8)

Perez-Perez A, Maymo J, Duenas JL, Goberna R, Calvo JC, Varone C \& Sanchez-Margalet V 2008 Leptin prevents apoptosis of trophoblastic cells by activation of MAPK pathway. Archives of Biochemistry and Biophysics 477 390-395. (doi:10.1016/j.abb.2008.06.015)

Perez-Perez A, Maymo J, Gambino Y, Duenas JL, Goberna R, Varone C \& Sanchez-Margalet V 2009 Leptin stimulates protein synthesisactivating translation machinery in human trophoblastic cells. Biology of Reproduction 81 826-832. (doi:10.1095/biolreprod.109.076513)

Perez-Perez A, Gambino Y, Maymo J, Goberna R, Fabiani F, Varone C \& Sanchez-Margalet V 2010 MAPK and PI3K activities are required for leptin stimulation of protein synthesis in human trophoblastic cells. Biochemical and Biophysical Research Communications 396 956-960. (doi:10.1016/j.bbrc.2010.05.031)

Perez-Perez A, Maymo J, Gambino Y, Guadix P, Duenas JL, Varone C \& Sanchez-Margalet V 2013 Insulin enhances leptin expression in human trophoblastic cells. Biology of Reproduction 89 20. (doi:10.1095/ biolreprod.113.109348)

Perez-Perez A, Toro AR, Vilarino-Garcia T, Guadix P, Maymo JL, Duenas JL, Varone CL \& Sanchez-Margalet V 2016 Leptin reduces apoptosis triggered by high temperature in human placental villous explants: The role of the p53 pathway. Placenta 42 106-113. (doi:10.1016/j. placenta.2016.03.009)

Persson G, Melsted WN, Nilsson LL \& Hviid TVF 2017 HLA class Ib in pregnancy and pregnancy-related disorders. Immunogenetics 69 581-595. (doi:10.1007/s00251-017-0988-4)

Pollheimer J \& Knofler M 2005 Signalling pathways regulating the invasive differentiation of human trophoblasts: a review. Placenta $\mathbf{2 6}$ (Supplement A) S21-S30. (doi:10.1016/j.placenta.2004.11.013)

Porter W, Saville B, Hoivik D \& Safe S 1997 Functional synergy between the transcription factor $\mathrm{Sp} 1$ and the estrogen receptor. Molecular Endocrinology 11 1569-1580. (doi:10.1210/mend.11.11.9916)

PrabhuDas M, Bonney E, Caron K, Dey S, Erlebacher A, Fazleabas A, Fisher S, Golos T, Matzuk M, McCune JM et al. 2015 Immune mechanisms at the maternal-fetal interface: perspectives and challenges. Nature Immunology 16 328-334. (doi:10.1038/ni.3131)

Prives C \& Hall PA 1999 The p53 pathway. Journal of Pathology 187 112-126. (doi:10.1002/(SICI)1096-9896(199901)187:1<112::AIDPATH250>3.0.CO;2-3)

Puscheck EE, Awonuga AO, Yang Y, Jiang Z \& Rappolee DA 2015 Molecular biology of the stress response in the early embryo and its stem cells. Advances in Experimental Medicine and Biology 843 77-128. (doi:10.1007/978-1-4939-2480-6_4)

Rao CV 2001 An overview of the past, present, and future of nongonadal $\mathrm{LH} / \mathrm{hCG}$ actions in reproductive biology and medicine. Seminars in Reproductive Medicine 19 7-17. (doi:10.1055/s-2001-13906)

Reitman ML, Bi S, Marcus-Samuels B \& Gavrilova O 2001 Leptin and its role in pregnancy and fetal development - an overview. Biochemical Society Transactions 29 68-72. (doi:10.1042/bst0290068)

Renstrom E, Eliasson L \& Rorsman P 1997 Protein kinase A-dependent and -independent stimulation of exocytosis by CAMP in mouse pancreatic B-cells. Journal of Physiology 502 105-118. (doi:10.1111/j.14697793.1997.105bl.x)

Safe S 2001 Transcriptional activation of genes by 17 beta-estradiol through estrogen receptor-Sp1 interactions. Vitamins and Hormones 62 231-252.

Safe S \& Kim K 2008 Non-classical genomic estrogen receptor (ER)/ specificity protein and ER/activating protein-1 signaling pathways. Journal of Molecular Endocrinology 41 263-275. (doi:10.1677/JME-080103)

Sagawa N, Yura S, Itoh H, Mise H, Kakui K, Korita D, Takemura M, Nuamah MA, Ogawa Y, Masuzaki H et al. 2002 Role of leptin in pregnancy - a review. Placenta 23 (Supplement A) S80-S86. (doi:10.1053/plac.2002.0814)

Saltiel AR \& Pessin JE 2002 Insulin signaling pathways in time and space. Trends in Cell Biology 12 65-71. (doi:10.1016/S0962-8924(01)02207-3)

Schanton M, Maymó J, Pérez-Pérez A, Gambino Y, Maskin B, Dueñas JL, Sánchez-Margalet V \& Varone C 2017 Sp1 transcription factor is a modulator of estradiol leptin induction in placental cells. Placenta $\mathbf{5 7}$ 152-162. (doi:10.1016/j.placenta.2017.07.005)

Senaris R, Garcia-Caballero T, Casabiell X, Gallego R, Castro R, Considine RV, Dieguez C \& Casanueva FF 1997 Synthesis of leptin in human placenta. Endocrinology 138 4501-4504. (doi:10.1210/ endo.138.10.5573)

Sferruzzi-Perri AN \& Camm EJ 2016 The programming power of the placenta. Frontiers in Physiology 7 33. (doi:10.3389/fphys.2016.00033)

Sharp AN, Heazell AE, Crocker IP \& Mor G 2010 Placental apoptosis in health and disease. American Journal of Reproductive Immunology 64 159-169. (doi:10.1111/j.1600-0897.2010.00837.x)

Shaywitz AJ \& Greenberg ME 1999 CREB: a stimulus-induced transcription factor activated by a diverse array of extracellular signals. Annual Review of Biochemistry 68 821-861. (doi:10.1146/annurev.biochem.68.1.821)

Sirois J \& Richards JS 1993 Transcriptional regulation of the rat prostaglandin endoperoxide synthase 2 gene in granulosa cells. Evidence for the role of a cis-acting C/EBP beta promoter element. Journal of Biological Chemistry 268 21931-21938.

Staples KJ, Bergmann M, Tomita K, Houslay MD, McPhee I, Barnes PJ, Giembycz MA \& Newton R 2001 Adenosine 3', 5'-cyclic monophosphate (cAMP)-dependent inhibition of IL-5 from human T lymphocytes is not mediated by the CAMP-dependent protein kinase A. Journal of Immunology 167 2074-2080. (doi:10.4049/jimmunol.167.4.2074)

Strauss JF 3rd, Kido S, Sayegh R, Sakuragi N \& Gafvels ME 1992 The cAMP signalling system and human trophoblast function. Placenta $\mathbf{1 3}$ 389-403. (doi:10.1016/0143-4004(92)90047-W)

Su RW \& Fazleabas AT 2015 Implantation and establishment of pregnancy in human and nonhuman primates. Advances in Anatomy, Embryology and Cell Biology 216 189-213. (doi:10.1007/978-3-319-15856-3_10)

Takahashi Y, Okimura Y, Mizuno I, lida K, Takahashi T, Kaji H, Abe H \& Chihara K 1997 Leptin induces mitogen-activated protein kinasedependent proliferation of C3H10T1/2 cells. Journal of Biological Chemistry 272 12897-12900. (doi:10.1074/jbc.272.20.12897)

Tanabe K, Okuya S, Tanizawa Y, Matsutani A \& Oka Y 1997 Leptin induces proliferation of pancreatic beta cell line MIN6 through activation of mitogen-activated protein kinase. Biochemical and Biophysical Research Communications 241 765-768. (doi:10.1006/bbrc.1997.7894)

Tartaglia LA, Dembski M, Weng X, Deng N, Culpepper J, Devos R, Richards GJ, Campfield LA, Clark FT, Deeds J et al. 1995 Identification 
and expression cloning of a leptin receptor, OB-R. Cell 83 1263-1271. (doi:10.1016/0092-8674(95)90151-5)

Tessier DR, Ferraro ZM \& Gruslin A 2013 Role of leptin in pregnancy: consequences of maternal obesity. Placenta 34 205-211. (doi:10.1016/j. placenta.2012.11.035)

Toro AR, Maymo JL, Ibarbalz FM, Perez-Perez A, Maskin B, Faletti AG, Sanchez-Margalet V \& Varone CL 2014 Leptin is an anti-apoptotic effector in placental cells involving p53 downregulation. PLOS ONE $\mathbf{9}$ e99187. (doi:10.1371/journal.pone.0099187)

Toro AR, Perez-Perez A, Corrales Gutierrez I, Sanchez-Margalet V \& Varone CL 2015 Mechanisms involved in p53 downregulation by leptin in trophoblastic cells. Placenta 36 1266-1275. (doi:10.1016/j. placenta.2015.08.017)

Umayahara $Y$, Kawamori R, Watada H, Imano E, Iwama N, Morishima T, Yamasaki Y, Kajimoto Y \& Kamada T 1994 Estrogen regulation of the insulin-like growth factor I gene transcription involves an AP-1 enhancer. Journal of Biological Chemistry 269 16433-16442.

Vickers MH \& Sloboda DM 2012 Leptin as mediator of the effects of developmental programming. Best Practice and Research: Clinical Endocrinology and Metabolism 26 677-687. (doi:10.1016/j. beem.2012.03.005)

Wade CB, Robinson S, Shapiro RA \& Dorsa DM 2001 Estrogen receptor (ER)alpha and ERbeta exhibit unique pharmacologic properties when coupled to activation of the mitogen-activated protein kinase pathway. Endocrinology 142 2336-2342. (doi:10.1210/endo.142.6.8071)
Wade M, Li YC \& Wahl GM 2013 MDM2, MDMX and p53 in oncogenesis and cancer therapy. Nature Reviews Cancer 13 83-96. (doi:10.1038/nrc3430)

Waterland RA \& Michels KB 2007 Epigenetic epidemiology of the developmental origins hypothesis. Annual Review of Nutrition 27 363-388. (doi:10.1146/annurev.nutr.27.061406.093705)

Weisz A \& Rosales R 1990 Identification of an estrogen response element upstream of the human c-fos gene that binds the estrogen receptor and the AP-1 transcription factor. Nucleic Acids Research 18 5097-5106. (doi:10.1093/nar/18.17.5097)

Yura S, Sagawa N, Ogawa Y, Masuzaki H, Mise H, Matsumoto T, Ebihara K, Fujii S \& Nakao K 1998 Augmentation of leptin synthesis and secretion through activation of protein kinases $\mathrm{A}$ and $\mathrm{C}$ in cultured human trophoblastic cells. Journal of Clinical Endocrinology and Metabolism 83 3609-3614. (doi:10.1210/jcem.83.10.5181)

Zhang Y, Proenca R, Maffei M, Barone M, Leopold L \& Friedman JM 1994 Positional cloning of the mouse obese gene and its human homologue. Nature 372 425-432. (doi:10.1038/372425a0)

Received 15 August 2017

First decision 28 September 2017

Revised manuscript received 28 September 2017

Accepted 9 October 2017 